\title{
Maculopathy caused by pentosan polysulfate
}

\author{
Daniel Rosenberg BSc, David Sarraf MD, Varun Chaudhary MD
}

Cite as: CMAJ 2021 May 3;193:E645. doi: 10.1503/cmaj.201900

\section{Pentosan polysulfate (PPS) is a mainstay for treatment of \\ 1. bladder pain associated with interstitial cystitis \\ Interstitial cystitis is a chronic bladder disorder causing pelvic pain and urinary frequency or urgency, with an estimated prevalence of 2.7\%-6.5\% among adult women. ${ }^{1}$ Pentosan polysulfate may buffer the bladder epithelium against irritants and is the only oral medica- tion approved by Health Canada for treatment of interstitial cyst- itis. ${ }^{1}$ It is typically administered orally at a dose of $100 \mathrm{mg} 3$ times daily.}

2 Maculopathy is associated with longer duration of PPS use A large retrospective study noted an increased likelihood of macular disease after 7 years of cumulative PPS exposure (odds ratio 1.41, 95\% confidence interval 1.09-1.83). ${ }^{2}$ A cross-sectional study of 50 patients with history of PPS therapy found that $15 \%-20 \%$ exhibited evidence of macular toxicity with formal retinal imaging. The prevalence of macular disease increased to $50 \%$ among patients with cumulative doses exceeding $1500 \mathrm{~g} .^{3}$

\section{3}

\section{Maculopathy caused by PPS may masquerade as age- \\ related macular degeneration}

Maculopathy caused by PPS is associated with difficulty reading and poor vision in low-light conditions. Patients with PPS maculopathy are often given diagnoses of more common conditions, such as agerelated macular degeneration. ${ }^{2}$

4

\section{Macular disease may progress even after cessation of PPS}

The proposed pathogenesis of PPS maculopathy involves disruption of the extracellular matrix surrounding the photoreceptors or direct toxicity to the retinal pigment epithelium..$^{2-4}$ It remains unclear whether disease trajectory is altered by drug cessation. ${ }^{4}$ Case series have documented progressive maculopathy for up to 6 years following discontinuation of PPS. ${ }^{5}$

\section{Patients exposed to PPS who report disturbed vision should undergo ophthalmic screening}

Prescribers of PPS and primary care providers should be aware that the Canadian Urological association suggests such screening. ${ }^{5}$ More recent ocular studies have recommend baseline retinal examination and imaging, especially in patients with cumulative PPS exposure greater than $500 \mathrm{~g}$, but more evidence is required to further refine screening guidelines. ${ }^{3,5}$

\section{References}

1. Cox A, Golda N, Nadeau G, et al. CUA guideline: Diagnosis and treatment of interstitial cystitis/bladder pain syndrome. Can Urol Assoc J 2016;10:E136-55.

2. Jain N, Li AL, Yu Y, et al. Association of macular disease with longterm use of pentosan polysulfate sodium: findings from a US cohort. Br J Ophthalmol 2020;104:1093-7.

3. Wang D, Au A, Gunnemann F, et al. Pentosan-associated maculopathy: prevalence, screening guidelines, and spectrum of findings based on prospective multimodal analysis. Can J Ophthalmol 2020;55:116-25.

4. Yusuf IH, Charbel Issa P, Lotery AJ. Pentosan polysulfate maculopathy - prescribers should be aware. JAMA Ophthalmol 2020;138:900-2.

5. Doiron RC, Bona M, Nickel JC. Possible drug-induced, visionthreatening maculopathy secondary to chronic pentosan polysulfate sodium (Elmiron") exposure. Can Urol Assoc J 2020;14:10-1.

Competing interests: Varun Chaudhary has served on the advisory board and as a consultant for Novartis and Bayer. He has investigator-sponsored research grants and participates in clinical trials funded by Novartis, Bayer and Allergan. David Sarraf has consulted for Amgen, Bayer, Genentech, Novartis and Optovue, and receives research grants from Amgen, Genentech, Heidelberg, Optovue, Regeneron and Topcon. No other competing interests were declared.

This article has been peer reviewed.

Affiliations: Michael G. DeGroote School of Medicine (Rosenberg), McMaster University, Hamilton, Ont.; Stein Eye Institute (Sarraf), David Geffen School of Medicine, University of California Los Angeles; Greater Los Angeles Veterans Administration Healthcare Center (Sarraf), Los Angeles, Calif.; Division of Ophthalmology (Chaudhary), Department of Surgery, and Department of Health Research Methods, Evidence and Impact (HEI) (Chaudhary), McMaster University; St. Joseph's Healthcare Hamilton and McMaster University (Chaudhary), Hamilton, Ont.

Content licence: This is an Open Access article distributed in accordance with the terms of the Creative Commons Attribution (CC BY-NC-ND 4.0) licence, which permits use, distribution and reproduction in any medium, provided that the original publication is properly cited, the use is noncommercial (i.e., research or educational use), and no modifications or adaptations are made. See: https://creativecommons.org/licenses/by-nc-nd/4.0/

Correspondence to: Varun Chaudhary, vchaudh@mcmaster.ca 